\title{
Heartburn, Functional Dyspepsia, Anxiety/Depression, and Sleep Disturbances Are Associated With Clinically Significant Belching
}

\author{
Yasuhiro Fujiwara, ${ }^{1 *}$ Masatsugu Okuyama, ${ }^{2}$ Yasuaki Nagami, ${ }^{1}$ Koichi Taira, ${ }^{1}$ Hirotaka Ishizu, ${ }^{2}$ Osamu Takaishi, ${ }^{2}$ Hiroshi Sato, ${ }^{2}$ \\ and Toshio Watanabe ${ }^{1}$ \\ ${ }^{I}$ Department of Gastroenterology, Osaka City University Graduate School of Medicine, Osaka, Japan; and ${ }^{2}$ Department of Gastroenterology, \\ Kashiwara Municipal Hospital, Kashiwara, Japan
}

\section{Background/Aims}

Belching is the act of expelling gas from the stomach or esophagus noisily through the oral cavity. Although it is a physiological phenomenon, belching may also be a symptom of upper gastrointestinal diseases such as reflux esophagitis and functional dyspepsia (FD). A detailed epidemiology of belching has not yet been reported. The aim of this study is to examine the prevalence and clinical characteristics of clinically significant belching (CSB) in adults.

\section{Methods}

We analyzed 1998 subjects who visited the hospital for annual health checkups. Belching was evaluated by a simple question "Do you burp a lot?" and scored as 0 (never), 1 (occasionally), 2 (sometimes), 3 (often), or 4 (always). Subjects with CSB were defined as having scores $\geq 3$. We also collected the clinical parameters, endoscopic findings, and data according to the Athens Insomnia Scale, Rome IV questionnaire, and Hospital Anxiety and Depression Scale (HADS).

\section{Results}

Of the 1998 subjects, 121 (6.1\%) had CSB. Subjects with CSB had FD more commonly than reflux esophagitis, but presence of heartburn was high (10.7\% vs 3.1\%). In addition, the HADS and Athens Insomnia Scale scores in subjects with CSB were significantly higher than those in subjects without CSB. Presence of heartburn (OR, 2.07; $95 \% \mathrm{Cl}, 1.05-4.09)$, presence of $\mathrm{FD}(\mathrm{OR}, 2.12 ; 95 \% \mathrm{Cl}$, 1.33-3.36), anxiety/depression (OR, 2.29; 95\% Cl 1.51-3.45), and sleep disturbances (OR, 1.73; $95 \% \mathrm{Cl}, 1.14-2.61)$ were significantly associated with CSB.

\section{Conclusion}

The detailed epidemiology of belching in the general adult population was clarified.

(J Neurogastroenterol Motil 2021;27:581-587)

\section{Key Words}

Anxiety; Depression; Dyspepsia; Eructation; Sleep

\section{Received: September 30, 2020 Revised: December 29, 2020 Accepted: February 18, 2021}

(a) This is an Open Access article distributed under the terms of the Creative Commons Attribution Non-Commercial License (http://creativecommons. org/licenses/by-nc/4.0) which permits unrestricted non-commercial use, distribution, and reproduction in any medium, provided the original work is properly cited.

${ }^{*}$ Correspondence: Yasuhiro Fujiwara, MD Department of Gastroenterology, Osaka City University Graduate School of Medicine, 1-4-3 Asahimachi, Abenoku, Osaka 5458585 , Japan Tel: +81-6-6645-3810, Fax: +81-6-6645-3813, E-mail: yasu@med.osaka-cu.ac.jp 


\section{Introduction}

Belching is the act of expelling gas from the stomach or esophagus noisily through the oral cavity, ${ }^{1,2}$ and healthy adults experience belching as a physiological phenomenon. Belching is not a specific symptom of upper gastrointestinal (GI) diseases, but patients with reflux esophagitis (RE) commonly complain of belching ${ }^{3}$ since gastroesophageal reflux and gastric belching are caused by transient lower esophageal sphincter relaxation. ${ }^{4}$ In addition, $59-80 \%$ of patients with functional dyspepsia (FD) reported frequent belching. ${ }^{5,6}$ Several studies have reported the prevalence and clinical characteristics of reflux and dyspeptic symptoms in the general population. ${ }^{7-10}$ However, a detailed epidemiology of belching has not been established. The aim of this study is to examine the prevalence and clinical characteristics of clinically significant belching (CSB) and the association between CSB and RE, FD, psychological stress, and sleep disturbances in adults.

\section{Materials and Methods}

\section{Data}

This study was performed using data from our previous study. A detailed methodology has been previously described. ${ }^{8}$ Data of 1998 Japanese subjects with annual health checkups at Kashiwara Municipal Hospital were analyzed. These included clinical parameters such as age, sex, smoking and alcohol drinking status, upper GI endoscopy findings, and the results of a self-report questionnaire comprising a frequency scale for the symptoms of gastroesophageal reflux disease (FSSG), ${ }^{11}$ Athens Insomnia Scale (AIS), ${ }^{12}$ Rome IV questionnaire, ${ }^{13}$ and Hospital Anxiety and Depression Scale (HADS) ${ }^{14}$ Patients who continuously used acid-suppressing drugs, had active peptic ulcer disease, or had a history of upper GI surgery were excluded. This study was approved by the Ethics Committee of Kashiwara Municipal Hospital (IRB No. 23-18). Written informed consent was obtained from all subjects, and all procedures were performed in accordance with the Declaration of Helsinki.

\section{Definition of Reflux Esophagitis and Functional Dyspepsia}

$\mathrm{RE}$ was defined as the presence of an esophageal mucosal break, according to the Los Angeles classification (grade A and above). ${ }^{15} \mathrm{FD}$ was defined as the absence of gastric lesions such as ulcers and erosions during upper GI endoscopy and fulfilled criteria according to the Rome $I V{ }^{13}$ FD was subdivided into epigastric syndrome (EPS) and postprandial distress syndrome (PDS) based on the symptoms. ${ }^{13}$

\section{Assessment of Belching and Heartburn}

We evaluated the presence of belching by a simple question, "Do you burp a lot?", which is the 11th question on the FSSG. Belching was scored by its frequency: 0 (none), 1 (occasionally), 2 (sometimes), 3 (often), and 4 (always). ${ }^{11}$ Subjects with CSB were defined as having scores $\geq 3$. Frequency of heartburn was assessed by the first question "Do you have heartburn?" in the FSSG and scored using the same scale of belching. ${ }^{11}$ Similarly, presence of significant heartburn was defined as scores $\geq 3$.

\section{Statistical Methods}

Values are expressed as mean $\pm \mathrm{SD}$ and numbers (percentages) for continuous and categorical variables, respectively. Categorical data were compared between groups using the chi-square test, while data from each group were statistically analyzed using the Kruskal-Wallis test. $P$-values $<0.05$ were considered significant. The association between belching and heartburn frequency was assessed using the Pearson correlation coefficient. A backward stepwise multiple logistic regression model was created to identify the independent factors associated with CSB. First, we analyzed several factors including age ( $<65$ or $\geq 65$ years), sex (male or female), body mass index (BMI) calculated by body weight divided by the squared height $\left(<25 \mathrm{~kg} / \mathrm{m}^{2}\right.$ or $\left.\geq 25 \mathrm{~kg} / \mathrm{m}^{2}\right)$, waist circumference ( $<85 \mathrm{~cm}$ or $\geq 85 \mathrm{~cm}$ ), smoking habits (current smoker or nonsmoker), alcohol consumption habits (frequent drinker or infrequent/nondrinker), RE (present or absent), heartburn (present or absent), AIS scores ( $<6$ or $\geq 6$, absence or presence of sleep disturbances), ${ }^{8} \mathrm{FD}$ (present or absent based on Rome IV criteria), and HADS scores ( $<8$ or $\geq 8$, absence or presence of anxiety/ depression).$^{10}$ We calculated the odds ratio (OR) with $95 \%$ confidence intervals (CI) and excluded statistically insignificant factors using the Wald test. All statistical analyses were performed using EZR (Saitama Medical Center, Jichi Medical University, Saitama, Japan), a graphical user interface for R (The R Foundation for Statistical Computing, Vienna, Austria). More precisely, it is a modified version of $\mathrm{R}$ commander designed to add statistical functions frequently used in biostatistics. ${ }^{16}$ 


\section{Results}

\section{Prevalence of Belching and Clinical Characteristics in Adults}

Figure 1 shows the prevalence of belching in adults. Among 1998 subjects, 28 (1.4\%) always experienced belching, 93 (4.7\%) often, $226(11.3 \%)$ sometimes, and 463 (23.2\%) occasionally. This shows that $121(6.1 \%)$ subjects had CSB. The clinical parameters of the subjects according to the frequency of belching are shown in Table 1. When we compared clinical factors between subjects with and without CSB, we found that subjects with CSB had FD more commonly than RE. However, presence of heartburn was significantly higher in subjects with CSB compared with those without CSB. There were no significant differences in age, sex, BMI, waist circumference, and smoking or alcohol consumption habits between

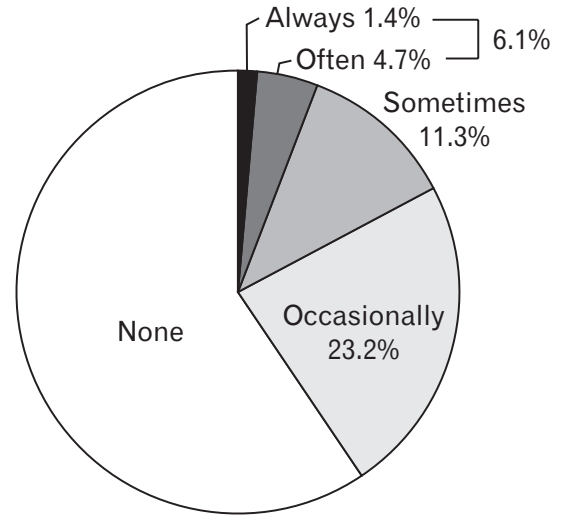

Figure 1. Prevalence of belching in adults. the 2 groups (Table 2).

\section{Association Between Belching and Severity of Reflux Esophagitis or Heartburn}

RE was found in 265 (13.3\%) subjects, including 204 (10.2\%) with grade A, 53 (2.7\%) with grade $\mathrm{B}$, and $8(0.4 \%)$ with grade $\mathrm{C}$. The prevalence of $\mathrm{RE}$ and its severity according to the frequency of belching is shown in Figure 2A. The prevalence of RE did not change among subjects with belching $(P=0.312)$, and the severity of $\mathrm{RE}$ did not correlate with the frequency of belching. Figure $2 \mathrm{~B}$ shows the association of frequency between belching and heartburn. There was a weak positive correlation between the frequency of belching and heartburn $(r=0.338)$.

Table 2. Clinical Characteristics of Clinically Significant Belching

\begin{tabular}{lccr}
\hline \multicolumn{1}{c}{ Factors } & $\begin{array}{c}\mathrm{CSB}(-) \\
(\mathrm{n}=1877)\end{array}$ & $\begin{array}{c}\text { CSB }(+) \\
(\mathrm{n}=121)\end{array}$ & $P$-value \\
\hline Age $(\mathrm{yr})$ & $61.2 \pm 11.9$ & $59.7 \pm 13.7$ & 0.062 \\
Male sex & $1073(57)$ & $64(53)$ & 0.394 \\
BMI $\left(\mathrm{kg} / \mathrm{m}^{2}\right)$ & $23.0 \pm 3.3$ & $23.0 \pm 3.3$ & 0.954 \\
Waist circumference $(\mathrm{cm})$ & $83.8 \pm 21.2$ & $82.9 \pm 9.2$ & 0.673 \\
Alcohol drinkers & $416(22)$ & $31(26)$ & 0.369 \\
Cigarette smokers & $303(16)$ & $18(15)$ & 0.799 \\
Presence of RE & $255(14)$ & $10(8)$ & 0.098 \\
Presence of heartburn & $59(3)$ & $13(11)$ & $<0.001$ \\
Presence of FD & $196(10)$ & $33(27)$ & $<0.001$ \\
HADS score & $6.8 \pm 5.5$ & $10.1 \pm 6.2$ & $<0.001$ \\
AIS score & $5.2 \pm 3.3$ & $3.5 \pm 3.1$ & $<0.001$ \\
\hline
\end{tabular}

CSB, clinically significant belching; BMI, body mass index; RE, reflux esophagitis; FD, functional dyspepsia; HADS, Hospital Anxiety and Depression Scale; AIS, Athens Insomnia Scale.

Data are presented as mean $\pm \mathrm{SD}$ or $\mathrm{n}(\%)$.

Table 1. Clinical Characteristics of the Study Subjects

\begin{tabular}{|c|c|c|c|c|c|}
\hline \multirow[b]{2}{*}{ Factors } & \multicolumn{5}{|c|}{ Frequency of belching } \\
\hline & $\begin{array}{c}\text { None } \\
(\mathrm{n}=1188)\end{array}$ & $\begin{array}{l}\text { Occasionally } \\
(\mathrm{n}=463)\end{array}$ & $\begin{array}{l}\text { Sometimes } \\
(\mathrm{n}=226)\end{array}$ & $\begin{array}{c}\text { Often } \\
(\mathrm{n}=93)\end{array}$ & $\begin{array}{l}\text { Always } \\
(\mathrm{n}=28)\end{array}$ \\
\hline Age (yr) & $61.7 \pm 11.9$ & $60.2 \pm 11.8$ & $60.7 \pm 12.0$ & $60.5 \pm 13.1$ & $54.6 \pm 15.2$ \\
\hline Male sex & $654(55)$ & $265(57)$ & $154(68)$ & $51(5)$ & $13(46)$ \\
\hline $\operatorname{BMI}\left(\mathrm{kg} / \mathrm{m}^{2}\right)$ & $23.0 \pm 3.3$ & $23.0 \pm 3.3$ & $22.7 \pm 3.7$ & $23.2 \pm 3.3$ & $22.4 \pm 3.4$ \\
\hline Waist circumference $(\mathrm{cm})$ & $84.1 \pm 25.5$ & $83.3 \pm 9.6$ & $82.6 \pm 10.4$ & $83.7 \pm 8.8$ & $80.4 \pm 11.4$ \\
\hline Alcohol drinkers & $252(21)$ & $109(24)$ & $52(23)$ & $24(26)$ & $10(25)$ \\
\hline Cigarette smokers & $190(16)$ & $69(15)$ & $44(19)$ & $11(12)$ & $7(25)$ \\
\hline Presence of RE & $151(13)$ & $69(15)$ & $35(15)$ & $8(9)$ & $2(7)$ \\
\hline Presence of FD & $93(8)$ & $61(13)$ & $42(19)$ & $23(25)$ & $10(36)$ \\
\hline
\end{tabular}

$\mathrm{BMI}$, body mass index; RE, reflux esophagitis; FD, functional dyspepsia.

Data are presented as mean $\pm \mathrm{SD}$ or $\mathrm{n}(\%)$. 


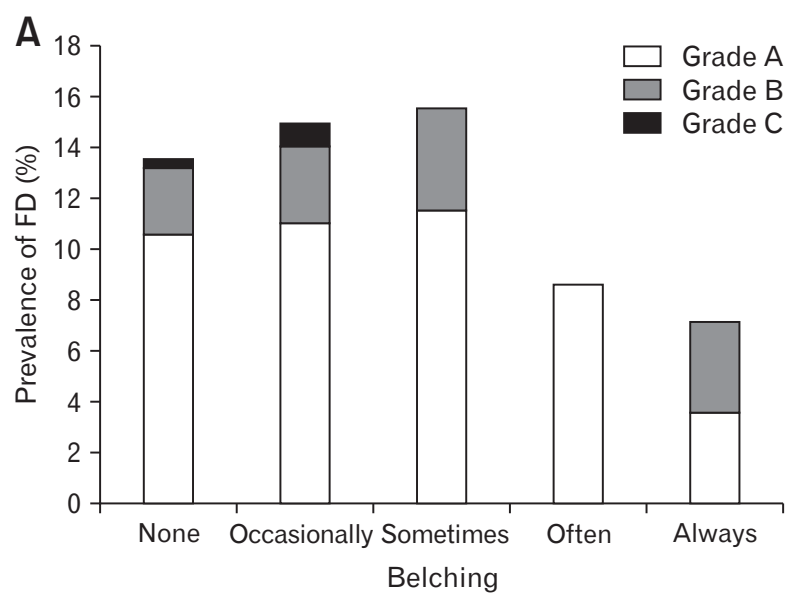

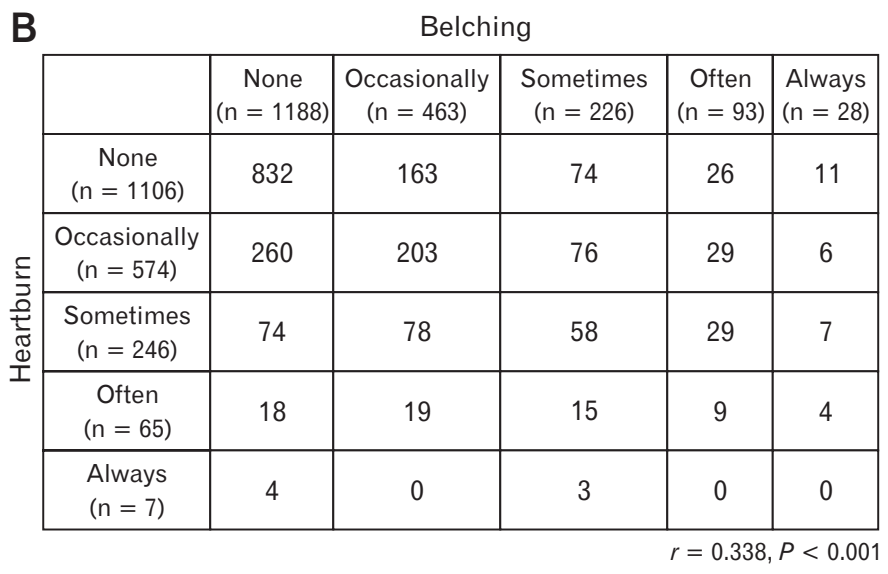

Figure 2. Association between belching and severity of reflux esophagitis or heartburn. (A) Prevalence of reflux esophagitis and its severity according to frequency of belching. (B) Frequency of belching is weakly correlated with the frequency of heartburn. FD, functional dyspepsia.
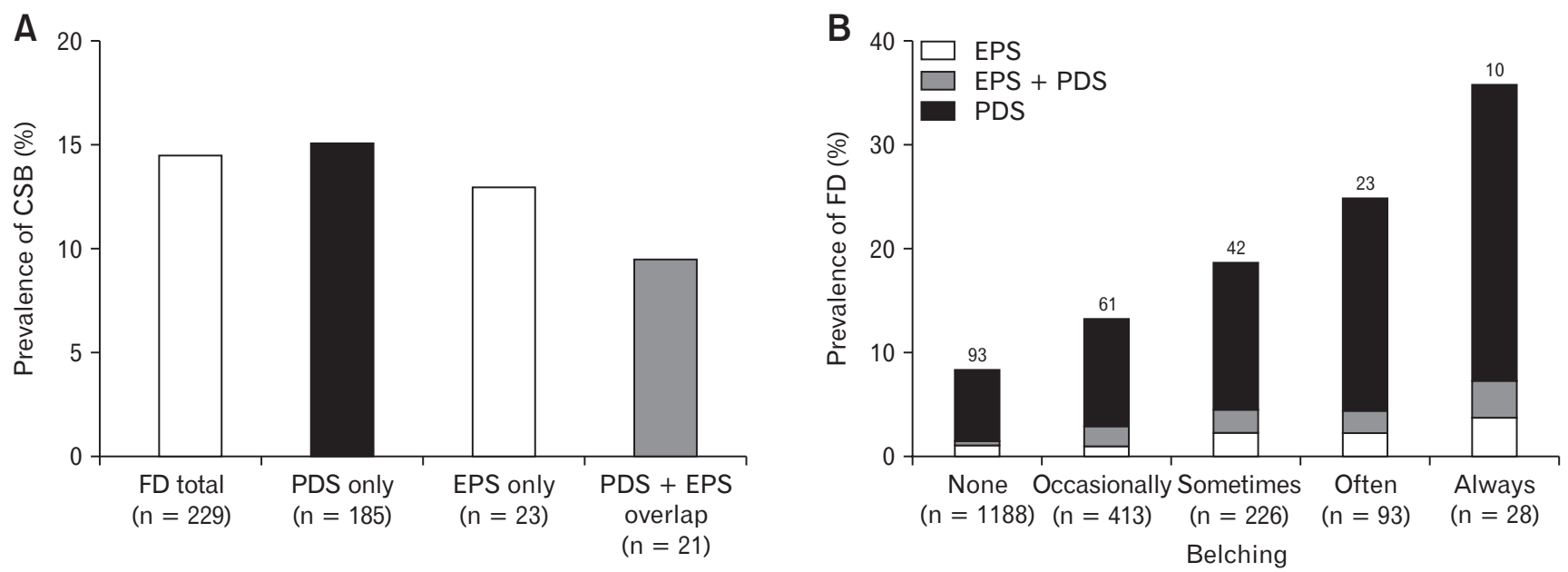

Figure 3. Prevalence of belching in functional dyspepsia (FD) subtypes and prevalence of FD according to frequency of belching. (A) There is no difference in the prevalence of clinically significant belching (CSB) in subjects with FD subtypes. (B) The prevalence of FD increased with the frequency of belching but the proportion of FD subtypes do not change. Number of cases with FD is shown in top of the bars. PDS, postprandial distress syndrome; EPS, epigastric pain syndrome.

\section{Prevalence of Belching in Functional Dyspepsia Subtypes and Prevalence of Functional Dyspepsia According to Frequency of Belching}

Among 229 FD subjects, FD subtypes included PDS ( $\mathrm{n}=$ 206), EPS ( $\mathrm{n}=44)$, and PDS + EPS $(\mathrm{n}=21)$. The prevalence of CSB was 30 (14.6\%) of 206 subjects with PDS, 5 (11.4\%) of 44 with EPS, and 2 (9.5\%) of 21 with overlap of PDS and EPS. There was no difference in belching among FD subtypes (Fig. 3A). The prevalence of FD increased with the frequency of belching, but the proportion of FD subtypes did not change (Fig. 3B).

\section{Association Between Frequency of Belching and Anxiety/Depression or Sleep Disturbances}

HADS and AIS scores in subjects with CSB were significantly higher than those in subjects without CSB (Table 2). Both the HADS and AIS scores were significantly higher in subjects with each frequency of belching but did not correlate with their frequencies (Fig. 4).

\section{Factors Associated With Belching}

Table 3 shows an analysis of the logistic regression model. Uni- 

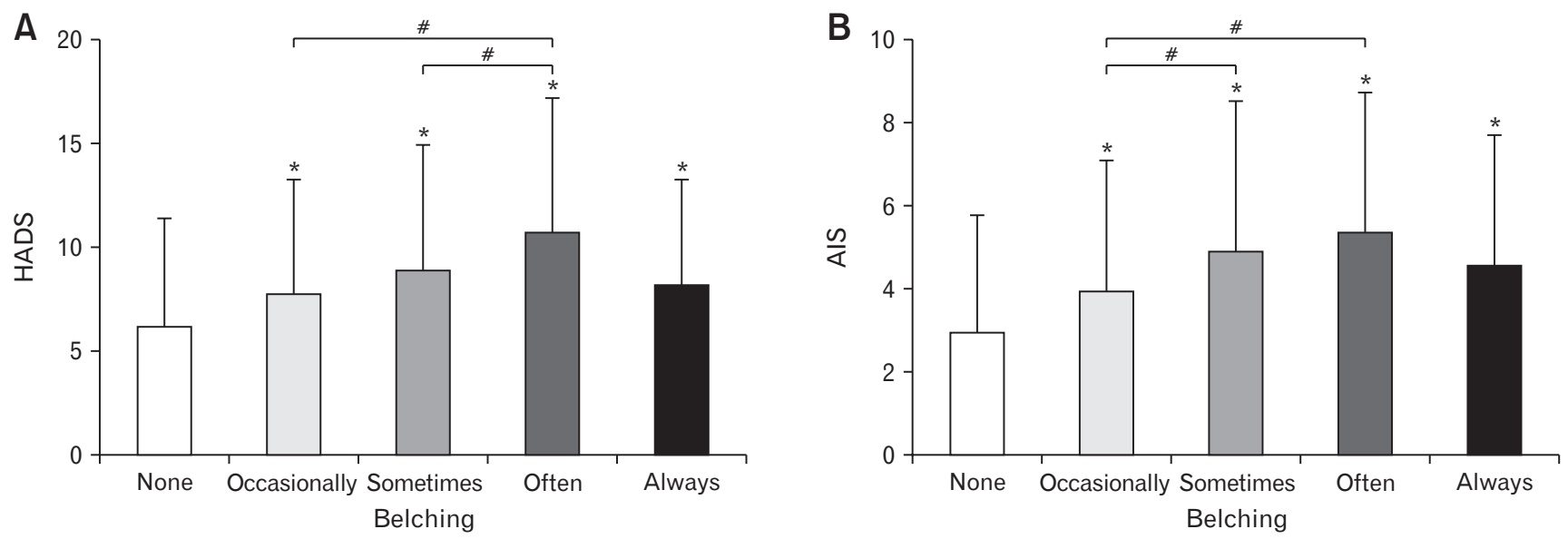

Figure 4. Association between frequency of belching and anxiety/depression or sleep disturbances. (A) Hospital Anxiety and Depression Scale (HADS) and (B) Athens Insomnia Scale (AIS) according to the frequency of belching. ${ }^{*} P<0.001$ belching present vs none. ${ }^{\#} P<0.001$.

Table 3. Risk Factors for Clinically Significant Belching

\begin{tabular}{|c|c|c|c|c|c|c|c|c|}
\hline \multirow{2}{*}{ Factors } & \multirow{2}{*}{$\begin{array}{c}\operatorname{CSB}(-) \\
(\mathrm{n}=1877)\end{array}$} & \multirow{2}{*}{$\begin{array}{l}\mathrm{CSB}(+) \\
(\mathrm{n}=121)\end{array}$} & \multicolumn{3}{|c|}{ Uni-variant analysis } & \multicolumn{3}{|c|}{ Multiple-adjusted analysis } \\
\hline & & & OR & $95 \% \mathrm{CI}$ & $P$-value & OR & $95 \% \mathrm{CI}$ & $P$-value \\
\hline Age $\geq 65 \mathrm{yr}$ & 938 & 61 & 1.02 & $0.69-1.50$ & $>0.999$ & & & \\
\hline Male gender & 1073 & 64 & 0.84 & $0.57-1.24$ & 0.394 & & & \\
\hline $\mathrm{BMI} \geq 25 \mathrm{~kg} / \mathrm{m}^{2}$ & 445 & 31 & 1.11 & $0.70-1.71$ & 0.66 & & & \\
\hline Waist circumference $\geq 85 \mathrm{~cm}$ & 789 & 57 & 1.28 & $0.83-1.81$ & 0.297 & & & \\
\hline Alcohol drinker & 413 & 34 & 1.39 & $0.89-2.12$ & 0.143 & & & \\
\hline Current smoker & 303 & 18 & 0.91 & $0.51-1.53$ & 0.799 & & & \\
\hline Presence of RE & 255 & 10 & 0.57 & $0.26-1.11$ & 0.098 & & & \\
\hline Presence of heartburn & 59 & 13 & 3.70 & $1.81-7.10$ & $<0.001$ & 2.07 & $1.05-4.09$ & $<0.001$ \\
\hline Presence of FD & 196 & 33 & 3.21 & $2.03-4.99$ & $<0.001$ & 2.12 & $1.33-3.36$ & $<0.001$ \\
\hline HADS score $\geq 8$ & 699 & 78 & 3.05 & $2.05-4.60$ & $<0.001$ & 2.29 & $1.51-3.45$ & $<0.001$ \\
\hline AIS score $\geq 6$ & 401 & 52 & 2.77 & $1.86-4.11$ & $<0.001$ & 1.73 & $1.14-2.61$ & $<0.001$ \\
\hline
\end{tabular}

CSB, clinically significant belching; BMI, body mass index; RE, reflux esophagitis; FD, functional dyspepsia; HADS, hospital anxiety and depression scale; AIS, Athens Insomnia Scale.

Table 4. Risk Factors for Belching According to Its Frequency

\begin{tabular}{lcccc}
\hline \multicolumn{1}{c}{ Factors } & \multicolumn{3}{c}{ Definition of belching } & \\
\cline { 2 - 5 } & $\geq$ Occasionally & $\geq$ Sometimes & NT & Always \\
\hline Male gender & $1.23(1.02-1.49)$ & $1.41(1.10-1.80)$ & NT \\
Presence of heartburn & $2.35(1.38-4.01)$ & $2.39(1.42-4.05)$ & $2.07(1.05-4.09)$ & \\
Presence of FD & $1.78(1.32-2.39)$ & $1.82(1.31-2.54)$ & $2.12(1.33-3.36)$ & $4.44(2.02-9.75)$ \\
HADS score $\geq 8$ & $1.56(1.28-1.90)$ & $1.66(1.29-2.15)$ & $2.29(1.51-3.45)$ & NT \\
AIS score $\geq 6$ & $1.71(1.36-2.15)$ & $2.22(1.69-2.91)$ & $1.73(1.14-2.61)$ & NT \\
\hline
\end{tabular}

FD, functional dyspepsia; HADS, hospital anxiety and depression scale; AIS, Athens Insomnia Scale; NT, not tested.

Data are presented as multiple-adjusted ORs (95\% CIs). 
variate analysis showed that presence of heartburn, presence of FD, anxiety/depression (HADS score $\geq 8$ ), and sleep disturbances (AIS score $\geq 6$ ) were significantly associated with CSB. After adjustment for statistical factors by univariate analysis, presence of heartburn, presence of FD, anxiety/depression, and sleep disturbances were significantly associated with CSB. We calculated the OR for belching according to its frequency. Subjects with belching $\geq$ occasionally or $\geq$ sometimes were associated with male sex in addition to same factor associated with CSB ( $\geq$ often), while only presence of FD was associated with belching always (Table 4).

\section{Discussion}

This is the first epidemiological study of belching in adults in detail. We found that the prevalence of CSB defined as $\geq$ often in frequency was $6.1 \%$. Presence of heartburn, presence of FD, anxiety/depression, and sleep disturbances were significantly associated with CSB, while age, sex, BMI, waist circumference, presence of RE, alcohol consumption, and smoking status were not. Particularly, the presence of FD was significantly associated with belching regardless of its frequency.

Although not specific, belching is a symptom in patients with FD. The present study showed that about $14.0 \%$ of subjects with FD reported $\mathrm{CSB}$, and there was no difference in the prevalence of CSB among FD subtypes. Pissevaux et $\mathrm{al}^{17}$ reported that 189 (50.0\%) of 378 subjects with dyspepsia complained of belching (104 mild, 64 moderate, and 21 severe). Carbone et $\mathrm{al}^{6}$ reported that the prevalence of belching in FD patients was $59.0 \%$ and a similar prevalence of belching among FD subtypes was observed (54.0\% in PDS, $44.0 \%$ in EPS, and $62.0 \%$ in overlap of PDS and EPS). Lower prevalence of belching in subjects with FD in this study was due to strict definition. Similar prevalence of belching among subjects with FD was observed when belching was defined as $\geq$ occasionally in this study $(136 / 229,59.3 \%)$.

The mechanism of the high prevalence of belching in subjects with FD should be discussed. Conchillo et $\mathrm{al}^{18}$ examined 10 patients with FD and 10 controls using esophageal impedance $\mathrm{pH}$ monitoring. They found that the incidence of air swallowing in patients with FD was significantly higher than that in controls. ${ }^{18}$ Gastric dysfunction in addition to air swallowing may be responsible for the high prevalence of belching in subjects with FD.

Although gastric belching is caused by transient lower esophageal sphincter relaxation, which is a major pathogenesis of $\mathrm{RE}{ }^{4}$ our study did not reveal a significantly high prevalence of belching in subjects with RE. Although a weak correlation of frequency between belching and heartburn was observed, presence of heartburn was significantly associated with CSB. The reasons for this discrepancy may be due to fact that belching with acid reflux causes heartburn in patients with non-erosive reflux diseases.

A high prevalence of anxiety disorders has been described in patients with excessive belching. Among such patients, belching often increases during stressful events. ${ }^{1,19}$ These findings may explain the positive association between anxiety/depression and the belching observed in this study. Anxiety/depression has been reported to be present in functional GI diseases and affects poorer health-related quality of life including sleep quality. ${ }^{20-22}$

Sleep disturbances are associated with several GI diseases, especially gastroesophageal reflux disease ${ }^{23}$ and FD. ${ }^{24,25}$ Although belching rarely occurs during sleep, we found a significant association between belching and sleep disturbances. Similarly, a recent study by Hyun et $\mathrm{al}^{26}$ demonstrated that sleep disturbances were associated with belching (OR, 1.59; 95\% CI, 1.24-2.03) in a crosssectional study of 4948 subjects. This may be related to the braingut axis, which is involved in the pathogenesis of functional GI disorders.

Male gender was identified as a significant risk factor of belching defined as $\geq$ occasionally or $\geq$ sometimes. The reasons for the male predominance in belching remain unclear. Saito et $\mathrm{al}^{27}$ reported that men eat food faster than women, suggesting that men may swallow air more often during eating. In addition, men may prefer carbonated alcoholic drinks, and they do not hesitate to belch when compared to women. Although there is no sex difference in excessive supragastric belching, ${ }^{1,2}$ male predominance may be seen in gastric belching, possibly physiological belching.

This study has some limitations. First, we assessed belching by exploring only the frequency of belching, but not whether belching is bothersome or not. We defined CSB as $\geq$ often, thus most of physiological belching may be excluded. In addition, there is currently no specific questionnaire for belching. It is difficult to evaluate the number of daily belches in an epidemiological study. Further study using a validated questionnaire for belching would be required. Second, we did not include other confounding factors that could affect belching. Factors such as intake of carbonated drinks and speed of food intake should be included in future studies. Third, belching is divided into 2 distinct types, namely gastric belching and supragastric belching. ${ }^{1,2}$ It is difficult to distinguish these 2 types of belching without esophageal impedance pH monitoring, ${ }^{1,228}$ although excessive supragastric belching could be diagnosed by medical interview such as frequency of belching (20-30 times per minute) and absence of belching during speech. ${ }^{28}$ 
However, it is especially impossible in an epidemiological study.

In conclusion, to our knowledge, this is the first report on the epidemiology of belching in adults in detail. We also clarified several clinical characteristics of CSB. Since excessive belching was associated with resistance against therapy, understanding the epidemiology of belching is important.

Financial support: This work was supported by Japan Society for the Promotion of Science KAKENHI (Grant No. 18K07917). The funders had no role in the study design, data collection and analysis, decision to publish, or preparation of the manuscript.

\section{Conflicts of interest: None.}

Author contributions: Yasuhiro Fujiwara designed the study protocol, performed data analysis, and wrote the draft of the manuscript; Masatsugu Okuyama collected data, performed data analysis, and participated in the manuscript writing; and Yasuaki Nagami, Koichi Taira, Hirotaka Ishizu, Osamu Takaishi, Hiroyuki Sato, and Toshio Watanabe supervised the entire project and reviewed the critical version of the manuscript. All authors approved the final version of the manuscript.

\section{References}

1. Bredenoord AJ. Management of belching, hiccups, and aerophagia. Clin Gastroenterol Hepatol 2013;11:6-12.

2. Kessing BF, Bredenoord AJ, Smout AJ. The pathophysiology, diagnosis and treatment of excessive belching symptoms. Am J Gastroenterol 2014;109:1196-1203.

3. Klauser AG, Schindlbeck NE, Müller-Lissner SA. Symptoms in gastrooesophageal reflux disease. Lancet 1990;335:205-208.

4. Dent J, Dodds WJ, Friedman RH, et al. Mechanism of gastroesophageal reflux in recumbent asymptomatic human subjects. J Clin Invest 1980;65:256-267.

5. Lin M, Triadafilopoulos G. Belching: dyspepsia or gastroesophageal reflux disease? Am J Gastroenterol 2003;98:2139-2145.

6. Carbone F, Vanuytsel T, Tack J. Analysis of postprandial symptom patterns in subgroups of patients with Rome III or Rome IV functional dyspepsia. Clin Gastroenterol Hepatol 2019;18:838-846, e3.

7. Fujiwara Y, Arakawa T. Epidemiology and clinical characteristics of GERD in the Japanese population. J Gastroenterol 2009;44:518-534.

8. Okuyama M, Takaishi O, Nakahara K, et al. Associations among gastroesophageal reflux disease, psychological stress, and sleep disturbances in Japanese adults. Scand J Gastroenterol 2017;52:44-49.

9. Aziz I, Palsson OS, Törnblom H, Sperber AD, Whitehead WE, Simrén M. Epidemiology, clinical characteristics, and associations for symptombased Rome IV functional dyspepsia in adults in the USA, Canada, and the UK: a cross-sectional population-based study. Lancet Gastroenterol
Hepatol 2018;3:252-262.

10. Oshima T, Miwa H. Epidemiology of functional gastrointestinal disorders in Japan and in the world. J Neurogastroenterol Motil 2015;21:320-329.

11. Kusano M, Shimoyama Y, Sugimoto S, et al. Development and evaluation of FSSG: frequency scale for the symptoms of GERD. J Gastroenterol 2004;39:888-891.

12. Soldatos CR, Dikeos DG, Paparrigopoulos TJ. Athens insomnia scale: validation of an instrument based on ICD-10 criteria. J Psychosom Res 2000;48:555-560.

13. Stanghellini V, Chan FK, Hasler WL, et al. Gastroduodenal disorders. Gastroenterology 2016;150:1380-1392.

14. Zigmond AS, Snaith RP. The hospital anxiety and depression scale. Acta Psychiatr Scand 1983;67:361-370.

15. Lundell LR, Dent J, Bennett JR, et al. Endoscopic assessment of oesophagitis: clinical and functional correlates and further validation of the Los Angeles classification. Gut 1999;45:172-180.

16. Kanda Y. Investigation of the freely available easy-to-use software 'EZR' for medical statistics. Bone Marrow Transplant 2013;48:452-458.

17. Piessevaux H, De Winter B, Louis E, et al. Dyspeptic symptoms in the general population: a factor and cluster analysis of symptom groupings. Neurogastroenterol Motil 2009;21:378-388.

18. Conchillo JM, Selimah M, Bredenoord AJ, Samsom M, Smout AJ. Air swallowing, belching, acid and non-acid reflux in patients with functional dyspepsia. Aliment Pharmacol Ther 2007;25:965-971.

19. Bredenoord AJ, Smout AJ. Impaired health-related quality of life in patients with excessive supragastric belching. Eur J Gastroenterol Hepatol 2010;22:1420-1423.

20. Kaji M, Fujiwara Y, Shiba M, et al. Prevalence of overlaps between GERD, FD and IBS and impact on health-related quality of life. J Gastroenterol Hepatol 2010;25:1151-1156.

21. Aro P, Talley NJ, Agréus L, et al. Functional dyspepsia impairs quality of life in the adult population. Aliment Pharmacol Ther 2011;33:1215-1224.

22. Park JK, Huh KC, Kwon JG, et al. Sleep disorders in patients with functional dyspepsia: a multicenter study from the Korean society of neurogastroenterology and motility. J Gastroenterol Hepatol 2021;36:687-693.

23. Fujiwara Y, Arakawa T, Fass R. Gastroesophageal reflux disease and sleep disturbances. J Gastroenterol 2012;47:760-769.

24. Lacy BE, Everhart K, Crowell MD. Functional dyspepsia is associated with sleep disorders. Clin Gastroenterol Hepatol 2011;9:410-414.

25. Futagami S, Yamawaki H, Izumi N, et al. Impact of sleep disorders in Japanese patients with functional dyspepsia (FD): nizatidine improves clinical symptoms, gastric emptying and sleep disorders in FD patients. J Gastroenterol Hepatol 2013;28:1314-1320.

26. Hyun MK, Baek Y, Lee S. Association between digestive symptoms and sleep disturbance: a cross-sectional community-based study. BMC Gastroenterol 2019;19:34.

27. Saito M, Shimazaki Y, Nonoyama T, Tadokoro Y. Number of teeth, oral self-care, eating speed, and metabolic syndrome in an aged Japanese population. J Epidemiol 2019;29:26-32.

28. Bredenoord AJ, Weusten BL, Sifrim D, Timmer R, Smout AJ. Aerophagia, gastric, and supragastric belching: a study using intraluminal electrical impedance monitoring. Gut 2004;53:1561-1565. 